\title{
Guaranización, sangre entreverada y no-humanos. Apuntes para no delimitar «lo guaraní» en el Ramal jujeño (Argentina)
}

\section{Sonia Elizabeth Sarra}

(iD) https.//orcid.org/0000-0003-4211-7947

Facultad de Filosofía y Letras, Universidad de Buenos Aires

soniaelisarra@gmail.com

RESUMEN

Este artículo indaga en las formas de socialidad guarani, humana y no-humana, en la región multiétnica del Ramal de la provincia de Jujuy (noroeste argentino). Especificamente, tiene por objetivo dar cuenta de la fluidez de los límites socioétnicos que distinguen «lo guarani» de lo que no lo es y la porosidad de los límites ontológicos que separan conjuntos humanos de otros no-humanos. En este texto, postulo la existencia de dos tipos de excesos de lo guaraní en la región que dificultan su encasillamiento y definición. El primero es de orden sociológico en sentido estricto y alude a la imposibilidad de delimitar la identidad guarani dentro de las comunidades y en función de las personas que explícitamente se identifican como guaranies. Es preciso ampliar lo guaraní hacia la población local mestiza, de «sangre entreverada» y guaranizada. El segundo exceso es de orden ontológico y se refiere a la ampliación de los lazos de socialidad hacia los pueblos no-humanos donde habitan los antepasados guaranies, devenidos dueños protectores de entidades del entorno.

Palabras clave: guaraní, no-humanos, alteridad, socialidad, noroeste argentino. 


\section{Guaranization, mixed blood and non-humans.} Notes not to delimit the «Guaraní» in Jujuy's Ramal (Argentinian Norwest)

\section{ABSTRACT}

This paper explores human and non-human forms of Guarani sociality in the multiethnic region of the Ramal in Jujuy (Argentinian Norwest). Specifically, it aims to show the fluidity of socio-ethnic limits that distinguish what is Guarani from what is not, and the porosity of ontological limits that differentiate humans from nonhumans. I argue that there are two Guarani excesses in the region, which make it difficult to classify and define Guarani borders. The first one is sociological in strict sense and refers to the impossibility of delimiting the Guarani identity within communities' borders and persons who explicitly identify themselves as "Guarani». It is necessary to expand the "Guarani» towards the local guaranized population of mixed blood. The second excess is ontological and refers to the expansion of social ties towards non-human worlds where Guarani ancestors, who become forest owners, live.

Keywords: Guarani, humans, non-humans, alterity, sociality, Argentinian Northwest 
INTRODUCCIÓN

«El problema es el Estado que delimita»

(Pïkïtü, pensador guaraní, año 2019).

Aquello que Pïkitü pronunció respecto del problema de la delimitación territorial para una sociedad «sin frontera» (Pïkïtü, 2019) permite reflexionar también sobre el problema de la definición de «lo guaraní» cuando nos enfrentamos a formas de experimentar la identidad sin límites precisos, en las cuales la alteridad es constitutiva. Este texto toma, como materia prima de análisis, fragmentos de historias de vida de pobladores locales (guaraníes, no-guaraníes, mestizos «con raíz indígena», personas «de sangre entreverada» y personas guaranizadas) del Ramal jujeño (noroeste argentino - NOA), diversas reflexiones de ellos en torno a lo «guaraní» en el Ramal, así como reflexiones sociocosmológicas de los guaraníes. La propia etnografía revela la fluidez de los límites socioétnicos que separan a las personas guaraníes de aquellas que no lo son (límites difusos que, incluso, operan al interior de una misma persona), y la porosidad de los límites ontológicos que distinguen conjuntos humanos de otros no-humanos (límites que pueden difuminarse, también, dentro de una misma persona). Unos y otros límites (socioétnicos y ontológicos, respectivamente) operan de modo contextual, provisorio y transformacional.

El carácter contextual y la relatividad de las categorías indígenas denominadas «étnicas» han sido señalados por Eduardo Viveiros de Castro: «as categorias indígenas de identidade coletiva têm aquela enorme variabilidade contextual de escopo característica dos pronomes [...]; sua coagulação como 'etnônimo' parece ser, em larga medida, um artefato produzido no contexto da interação com o etnógrafo» (1996, p. 125). En la primera parte de este texto, buscaré dar cuenta 
del dinamismo inherente a la categoría «guaraní», que más que etnónimo, puede ser entendida como término relacional que solo provisoria y contextualmente se aplica para designar a grupos delimitados en el Ramal jujeño (NOA). Decir «más que etnónimo» no cancela que, en determinadas situaciones, «guaraní» sea utilizado (efectivamente lo es) como etnónimo para designar a personas y comunidades. La categoría «guaraní» como etnónimo toma en consideración a quienes explícitamente se identifican como guaraníes y que, como tales, se afilian dentro de comunidades, pero se muestra limitada para incorporar a quienes, sin interés en definirse como guaraní ni participar en las comunidades, resultan una parte fundamental de la trama vital del mundo guaraní en Jujuy. Ancianos y ancianas ipaye reta («chamanes») son figuras clave en estos entramados $\mathrm{y}$, sin embargo, se recluyen por temor a salir de sus casas. En una oportunidad, una ipaye me expresó que lo guaraní, para ella, se encontraba dentro de su propia casa. Asimismo, muchos pobladores locales, pese a no identificarse como guaraníes, son figuras fundamentales en la regeneración de los lazos con los no-humanos. Quienes participan en el arete guasu (denominado popularmente pim pim) ${ }^{1}$ como enmascarados («mascaritas») no se reconocen todos ellos como guaraníes y, no obstante, cumplen un rol crucial en el recuerdo ritual de los antepasados guaraníes. Profundizaremos en estas cuestiones a lo largo de este texto; por el momento me interesa señalar que lo guaraní en el Ramal pareciera emerger, también, allí donde no siempre se explicita.

La participación de quienes podríamos calificar - en principio - como no-guaraníes en la regeneración de los lazos con los antepasados guaraníes nos introduce en la segunda dimensión que analizaré en este texto: la importancia de las aldeas no-humanas, y la alteridad de los antepasados y los kaa iya reta («dueños del monte») $)^{2}$. Los mundos no-humanos y sus habitantes constituyen un aspecto central en el entramado sociocosmológico guaraní. Así como la categoría «guaraní» requiere ser ampliada a quienes —en principio y según cierta perspectiva - no lo serían, la noción de humano también puede ser expandida más allá de los colectivos propiamente humanos. Por ambas vías, observo un exceso

1 Tradicionalmente fiesta de cosecha anual, en la actualidad el ritual del arete guasu (o pim pim) en Jujuy se celebra para mantener los vínculos con los antepasados y el ñande reko («modo de vida guaraní») en contextos urbanos y periurbanos. La festividad coincide con las fechas del carnaval y con los festejos y corsos provinciales de Jujuy.

2 En la etnografía sudamericana, la categoría «dueño» está ampliamente difundida y designa a entidades no-humanas con las cuales los humanos deben entablar relaciones de distinto tipo para, entre otras posibilidades, acceder a los recursos que dichas entidades poseen, administran y regulan. Ampliaremos la discusión en el apartado correspondiente. 
de «lo guaraní» en el Ramal jujeño: más allá de los límites de las comunidades guaraníes y, en un sentido ontológico, por fuera de las comunidades propiamente humanas. La delimitación de comunidades guaraníes, la afiliación de miembros a dichas comunidades y la autoadscripción étnica constituyen formas posibles de ser guaraní en Jujuy, formas, sin duda, relevantes en el ámbito político en lo que refiere a la relación de los pueblos indígenas con los Estados provincial y nacional, pero que pueden mostrarse insuficientes para captar otros tipos de socialidad ampliada: aquellos que parecieran no encasillarse cómodamente en «guaraní» y a los mundos no-humanos.

Es preciso «disminuir la velocidad de razonamiento» (Stengers, 2005) para delimitar de modo abierto estos dinamismos y estar advertidos acerca de las potencialidades de ser guaraní en el Ramal. Al respecto, Silvia Hirsch (2004a) reflexionó en torno a la identidad étnica guaraní en constante construcción y redefinición en el NOA. La autora se preguntó: «¿Cómo se define ser guaraní en el norte argentino? ¿Cómo se adscribe a una identidad indígena en una zona del país multiétnica, diversa, pero con un discurso unificador y en constante proceso de transformación?» (2004, p. 67).

Según su investigación, existen distintos modos de ser guaraní en esta región en relación con los contextos sociohistóricos diversos. Si en comunidades rurales como Yacuy (Salta) se observa una exaltación de lo guaraní (reflejada en la continuidad de la lengua indígena y de prácticas consideradas tradicionales), en otras comunidades urbanas de Tartagal (Salta) se registra una predominancia de la adscripción étnica indígena genérica y una disolución de lo guaraní frente al otro no indígena. Si bien las comunidades urbanas o periurbanas del Ramal se enfrentan también a procesos de entrevero y disolución, lo guaraní — al diluirse - se desparrama sobre la sociedad en general del Ramal, en una dinámica expansiva y guaranizadora.

En este texto me basaré en el trabajo etnográfico que realicé en la región subtropical de Jujuy, conocida como Las Yungas o el Ramal, donde numerosas comunidades guaraníes y mixtas colla-guaraníes se asientan «entreveradas» en ciudades y pueblos de los departamentos de Ledesma, Santa Bárbara y San Pedro, restringidas - en su mayoría - a barrios y predios comunitarios y rodeadas de hectáreas de cañaverales de azúcar de la empresa Ledesma. Según datos de referentes guaraníes, existen más de sesenta comunidades guaraníes y algunas mixtas colla-guaraníes en las tierras bajas de la provincia de Jujuy³. Principalmente,

Tal como sostiene Omar Jerez (2011), quienes poseen datos más acertados acerca de la cantidad de guaraníes en la región son las propias comunidades. De acuerdo a sus estimaciones, 
realicé trabajo de campo en dos comunidades periurbanas de la localidad de Calilegua (departamento de Ledesma): la comunidad guaraní Kuape Yayemboati y la comunidad colla-guaraní Hermanos Unidos. Si bien mi investigación se centró en el trabajo con familias de dichas comunidades, también incluyó a quienes no se encuentran afiliados o no participan en ellas. El Ramal es una región profundamente guaranizada en tanto la «composición de mundo» (sensu Descola, 2016) ${ }^{4}$ guaraní excede los límites de las comunidades y se derrama sobre la percepción del entorno, modos de ingresar al monte, prácticas de curación, modos de hacer política y de experimentar la historia de la población colla, mestiza y criolla. Es así que, por ejemplo, en Calilegua todos son conscientes del peligro que implica «pisar una porquería» - en general tierra de cementerio- que los curanderos ${ }^{5}$ indígenas pueden colocar en el camino de alguien con alguna intención. La guaranización de la región también se percibe en la época de la festividad guaraní del arete guasu, que atrae la atención y participación de la población de las localidades jujeñas en general.

\section{BREVE CONTEXTUALIZACIÓN: DE LA GUARANIZACIÓN HISTÓRICA A LA GUARANIZACIÓN ACTUAL}

Los guaraníes de Jujuy forman parte de un pueblo amerindio de ascendencia tupíguaraní, cuyo territorio corresponde a las estribaciones surorientales de los Andes de Argentina y de Bolivia. Al interior de los guaraníes, se diferencian tradicionalmente tres subgrupos en función de matices culturales y variantes dialectales:

la población guaraní en Jujuy ascendería a 33700 individuos. Según datos oficiales del año 2009, existirían veintiséis comunidades guaraníes en la provincia (Jerez, 2011) y, según la cartilla étnica realizada por Matilde García Moritán y María Beatriz Cruz (2012), tal número ascendería a 39 (de las cuales solo una es mixta colla-guaraní). Ahora bien, si se cotejan los datos de las propias comunidades, los referentes sostienen que existen más de sesenta comunidades guaraníes en la provincia. Debido a las dificultades para tramitar su personería jurídica, muchas de ellas carecen de reconocimiento ante el Estado y en su mayoría no poseen tierras. La excepción son 4172 tierras otorgadas a once comunidades en Vinalito; sin embargo, estas tierras no son aptas por falta de agua potable (Gordillo, 2010a; Santamaría, 2010).

4 «Composición de mundo» se vincula con el concepto de «ontología», entendido por Descola (2016) como la expresión concreta de cómo está compuesto un mundo particular, los existentes que lo pueblan y el tipo de relaciones que se tejen entre ellos.

5 «Curandero» puede significar, según el contexto semántico, al especialista que hace desaparecer una dolencia o la produce, que resuelve un conflicto o lo genera, que une a una pareja o la separa, entre otras acepciones. 
ava, simbas e isoseños. En líneas generales, mis interlocutores guaraníes adultos del Ramal desconocen, en su mayoría, a cuál pertenecen.

En la historiografía y la etnografía clásica, los guaraníes de esta región son conocidos como «chiriguanos» y como «chaguancos». En mis primeras aproximaciones a las comunidades de Calilegua, el mburuvicha («líder») de la Kuape Yayemboati me aclaró que ellos no se reconocen como chiriguanos ni como chaguancos, ya que se trata de nombres peyorativos ${ }^{6}$. Sin embargo, existen matices y divergencias en las maneras en que mis interlocutores se identifican a sí mismos. Algunos de ellos se llaman «chaguancos», pero ninguno se reconoce como «chiriguano». Cuando hoy en día los guaraníes eligen no autodenominarse «chiriguanos», no lo hacen solo por considerarlo un nombre impuesto, sino también para distanciarse del conjunto de ideas, estereotipos y relatos históricos asociados a dicho etnónimo. Entre estos elementos, se encuentra la aloctonía respecto del piedemonte andino y el origen mestizo que se les atribuye.

Hay común acuerdo entre historiadores y antropólogos respecto del origen mestizo de los chiriguanos ${ }^{7}$, quienes habrían surgido de la mezcla que se produjo entre dos grupos amerindios: los chané (de origen arawak) y los guaraníes provenientes desde Brasil y Paraguay (llegados al piedemonte andino en fechas imprecisas antes y después de la conquista). Diego Villar (2005) afirmó que hubo tanta guaranización de los chané como arawakización de los guaraníes: por un lado, la cultura arawak aportó, según el antropólogo argentino, la densidad demográfica, las mujeres y la fuerza masculina de trabajo, las técnicas de alfarería, riego y tejido, el enmascaramiento ritual y las jerarquías de estratificación social; por otro, la cultura guaraní aportó un gran número de motivos mitológicos y, fundamentalmente, el idioma (Villar, 2005). Branislava Susnik (1968) denominó a este proceso chiriguanización o ava-ización, y a la arawakización la denominó tapiización. Tapiti se traduce como «esclavos» y es por ello que alude a las poblaciones de origen arawak «conquistadas» por los guaraníes. En este proceso de mestizaje (denominado de distintas formas), se tiende a enfatizar la expansión e imposición de lo guaraní sobre las etnias locales.

Algunos autores han observado la tendencia homogeneizadora histórica y contemporánea de la guaranización: en el pasado prehispánico, cuando migrantes guaraníes habrían guaranizado a otras poblaciones pedemontanas locales, y en

6 «Chaguanco» podría ser un término de origen quechua, surgido en los ingenios para designar a los chiriguanos, que podría significar «piernas flacas» (Hirsch, 2004a).

7 Ver Combès y Villar (2007), Hirsch (2004a), Saignes (1990), Saignes y Combès (1991), Susnik (1968), Villar (2005), entre otros. 
la actualidad, cuando lo guaraní se impone y unifica bajo una misma identidad a diversos pueblos de la región. En este proceso contemporáneo, según Diego Villar (2013), tuvieron influencia especialistas misioneros (Bartomeu Melià, Francisco Pifarré y Xavier Albó), antropólogos, asesores y entidades como CIPCA (Centro de Investigación y Promoción del Campesinado de Bolivia) y APG (Asamblea Pueblo Guaraní $)^{8}$. Según Isabelle Combès (2005), estos agentes proyectaron su propia imagen idealizada de nación sobre los guaraníes. En una línea homogeneizadora, CIPCA habría promocionado una identidad panguaraní, formateada en torno a algunos clásicos conceptos como ñande reko, iyambae («sin dueño») e ivi maraei («tierra sin mal»), lo cual condujo a opacar las diferencias internas entre los subgrupos (ava, isoseños y simbas) y grupos emparentados a los guaraníes, como los chané (Villar 2013). La unidad política transnacional, bajo ciertos elementos homogéneos y en torno a organizaciones étnicas y supraétnicas (como APG y CCNAGUA) 9 , es percibida por diversos especialistas como una novedad absoluta debido a que representa una ruptura en la tradición política chiriguana con tendencia a la dispersión (Combès 2005, p. 45).

Según Hirsch, la reciente adopción del término «guaraní», y el concomitante rechazo de «chaguanco» y «chiriguano», se vincula con procesos políticos organizativos de los guaraníes (2004a). En Bolivia, se remontan a la década de 1980, cuando la población guaraní de la región oriental comenzó a utilizar el etnónimo «guaraní» para referirse a sí misma ${ }^{10}$. La difusión del término «guaraní» en el NOA tuvo lugar posteriormente. En consonancia con las reemergencias indígenas, el pluralismo étnico y el reconocimiento de la diversidad cultural que hace algunas décadas tiñen los escenarios latinoamericanos, los guaraníes de la región del NOA en general - y de Jujuy en particular - han comenzado, desde la década de 1990, un proceso de reafirmación étnica y visibilización frente a la sociedad envolvente (Gordillo, 2010a; Hirsch, 2004a; Santamaría, 2010). Por más que resulte evidente, cabe aclarar que del uso novedoso del etnónimo no se deduce la ausencia previa del pueblo guaraní en la región. Más allá de la generalización del término «guaraní» en ambos países, algunos de mis interlocutores de Jujuy se denominan a sí mismos, en ciertos contextos de la intimidad del hogar y la vida comunitaria, «chaguancos».

8 La APG, creada en 1987, nuclea a los guaraníes de Bolivia. También existe la APG de Mbaporenda (Argentina).

$9 \quad$ El CCNAGUA engloba a los guaraníes de Argentina, Bolivia, Paraguay y Brasil.

10 Sobre los vínculos entre guaraníes de Bolivia y Argentina, ver Hirsch (2000, 2014). 
Si bien la guaranización puede ser analizada en una dimensión étnico-política en lo que refiere a los procesos de unificación, centralización y reivindicación de lo «guaraní» en el piedemonte andino, también ella puede ser entendida en un sentido sociocosmológico más amplio. La guaranización se observa también en lo que, en este artículo, denomino «exceso» de lo guaraní en Jujuy: la población y la cosmología local del Ramal (aparentemente mestizas, entreveradas e indígenas genéricas) son guaranizadas, y lo guaraní se halla por fuera de las comunidades y más allá de los colectivos humanos. Podría afirmarse que, en el Ramal, lo guaraní se encuentra, también, en sus propios márgenes, en lo inclasificable y lo desbordante.

\section{EL ENTREVERO EN LOS INGENIOS AZUCAREROS Y EL PAISAJE MULTIÉTNICO DE CALILEGUA}

Al caminar por una de las principales calles de Calilegua (el bulevar de la calle Sarmiento), Victoria (una mujer de ascendencia colla, habitante de Calilegua) recuerda, con cierta nostalgia, «ahora cualquiera vive acá, pero antes la arquitectura estaba asociada a la categoría social». Dado que la categoría social estaba en cierta medida determinada por el carácter étnico, la arquitectura de Calilegua permite, por un lado, acceder a las antiguas divisiones entre distintos grupos o «razas», y por otro, contextualizar históricamente el panorama sociológico actual. La categoría nativa de «raza» es central en la sociológica guaraní y la «sangre» es un componente que, si bien no es definitorio de la «raza», es un criterio para clasificar «razas». Como veremos, la «raza» no está asociada a lo «dado» sino que es, en gran medida, construida. «Entrevero» y «entreverar» son categorías nativas que refieren al idioma de la mezcla, tanto biológica como cultural. «Ahora estamos entreverados», afirman frecuentemente mis interlocutores adultos y ancianos guaraníes de Calilegua. Esta expresión se refiere tanto a la disolución de los barrios exclusivamente guaraníes como a la mayor proporción de matrimonios étnicos mixtos antiguamente proscriptos por los ancianos guaraníes. De los antiguos barrios guaraníes al entrevero periurbano actual, y de la antigua pureza étnica al entrevero de «sangre», lo guaraní pareciera diluirse y perderse, pero, a la vez, como aseveró un referente guaraní del Ramal, «se encuentra por todos lados».

El escenario multiétnico actual se remonta a fines de siglo XIX y principios del $\mathrm{XX}$, cuando indígenas de casi todo el Chaco central, algunos del Chaco austral y boreal, y grupos indígenas del piedemonte y de tierras altas de Argentina y Bolivia, eran reclutados como mano de obra estacional, extremadamente barata, para el 
trabajo en los ingenios azucareros (Bossert, 2013; Gordillo, 2010). Sin dejar de ver en el arrinconamiento territorial las causas de estas migraciones laborales, numerosos autores han llamado la atención sobre la atracción que generaban estos viajes entre diversos grupos indígenas (Bossert, 2013; Braunstein y Miller, 1999; Gordillo, 2010b; Hirsch, 2004b; Langer, 2009) y que se explicaba, en parte, por la fascinación material que representaban los nuevos bienes, vestimentas, alimentos y estimulantes que allí se podrían adquirir, pero también por la experiencia social inédita que ofrecían los ingenios (Bossert, 2013). En efecto, muchos guaraníes asocian el comienzo del entrevero racial actual y la «degeneración de la raza»a la vida en los ingenios. «Nos fuimos entreverando» $\mathrm{y}$ «En Calilegua hay mucha mezcla de razas» son expresiones recurrentes tanto entre quienes se identifican como guaraníes como entre la población local karai («blanca»), colla y mestiza que no adscribe a ningún pueblo indígena. Ahora bien, el idioma de la mezcla y la pureza adquiere, entre los guaraníes, particularidades que buscaré esclarecer a lo largo de este texto.

Como desarrollaré en los próximos apartados, por un lado, lo guaraní puede mantenerse «puro» en el entrevero y, por otro, personas no guaraníes por nacimiento pueden ser guaranizadas. Este doble juego nos permitirá acercarnos a los fenómenos de sincretismo y mestizaje desde otros discursos que no presuponen la homogeneización inevitable. Por el contrario, estos contradiscursos ${ }^{11}$ procederían, siguiendo a Marcio Goldman (2017), a través de lo que él denomina modulación de la diversidad: «proceso de variación continua en el cual en la coexistencia de elementos diferentes puede haber un nivel en que ellos efectivamente se combinan, pero también niveles en que permanecen de algún modo distintos» (p. 16, traducción propia). En este sentido, se puede pensar que lo guaraní, por un lado, se mantiene como elemento discreto (visible o en latencia) dentro de una mezcla $y$, por otro, tiñe a la diferencia (es decir, se mezcla) con otros elementos. El doble juego (pureza/entrevero) permite analizar la paradoja que señalaron Combès y Villar (2007): de origen mestizo, los chané (y podría ampliarse a los guaraníes del piedemonte en general) exaltan una ideología de pureza (retomaremos esta cuestión en el siguiente apartado).

El escenario de los ingenios azucareros del NOA podría compararse al de las barracas caucheras de la Amazonia. Según observó Peter Gow (1991), los

11 Al respecto, Goldman (2017) propuso la noción de contramestizaje. Ver también José Kelly (2016), quien acuñó el concepto de antimestizaje, y Silvia Rivera Cusicanqui (2010) quien hace referencia a la yuxtaposición étnica sin fusión a través del concepto de ch'ixi. 
nativos del Bajo Urubamba (Amazonia peruana) aseveran frecuentemente que son «gente mezclada» $\mathrm{o}$ «de sangre mezclada». Al igual que entre mis interlocutores, el idioma de la «mixtura» que registró Gow refiere al colapso de la «gente pura» a través de matrimonios mixtos y la situación de contacto intensa (Gow, 1991). En este aspecto, se podrían comparar ambos escenarios (ingenios y barracas caucheras) en función de las perspectivas nativas acerca de la mezcla racial y la pérdida de pureza original. A primera vista, los discursos que exaltan la mixtura parecerían contrastar con los contradiscursos del mestizaje, que sostienen que ciertos elementos pueden permanecer discretos sin mezclarse. Sin embargo, no se trata de optar por uno u otro discurso (es decir, mestizaje o contramestizaje, entrevero o pureza), sino aceptar que ambos fenómenos suceden en simultáneo: si bien hay ciertas cosas que efectivamente son mezcladas, hay otras que parecieran permanecer intactas, en estado de latencia y «puras».

\section{Historias mezcladas. Guaranies entreverados y lo guarani en el entrevero}

Una tarde, mientras paseaba por el bulevar de Calilegua, me crucé con Miriam, sobrina de una reconocida curandera local, miembro de la comunidad Kuape Yayemboati y reina del pim pim en los corsos de 2019. Ese día, sobre unos tacones de veinte centímetros, con su melena rubia y una remera brillante, me confesó que siente orgullo de «ser chaguanca» y, que, aunque su «apariencia karai» diga lo contrario, ella es chaguanca. Su apariencia antiestereotipada pareciera no solo entreverar sangre karai y chaguanca, sino mundos, estilos y vestimentas. Miriam, como las demás mujeres guaraníes, tiene la versatilidad de usar el mandu (vestimenta típica guaraní) o jeans y tacones altos, según la ocasión. En determinados contextos, a Miriam — como a muchas guaraníes - le «salta la kuña ['mujer guaraní']» o «le tira la sangre [guaraní o chaguanca]». La expresión nativa «te salta la kuña» es utilizada por las mujeres para referirse a los contextos en que la indudable identidad guaraní sale a la luz y podría ser traducida como: «se evidencia tu ascendencia indígena». «Tira la sangre» es utilizada de manera similar en alusión al efecto que produce la «sangre» guaraní. Por ejemplo, es por esa «sangre» que resulta imposible, en términos de mis interlocutores, quedarse quieto cuando suena la música del pim pim. Miriam, como punto de partida, me conduce a reflexionar en torno a lo «guaraní» (o «lo chaguanco») como algo en estado de latencia que, sin mezclarse, puede expresarse u ocultarse, según la situación.

Esta dualidad de Miriam se repite en varias historias de vida de mujeres y hombres del Ramal, que entreveran «sangre» y mundos, sin fusionarlos totalmente. 
En sus discursos pareciera que la «sangre» guaraní corriese por una vía paralela (sin mezclarse) a las «otras sangres» y en el momento en que la sangre indígena «tira», se activa la identidad guaraní/chaguanca. Tal es el caso de Susana, una de mis anfitrionas durante mis estadías en Calilegua. De «sangre mezclada», trabajadora estatal de la Municipalidad de Calilegua, ex esposa de un concejal karai, actual novia de un hombre karai y desinteresada de la participación en las comunidades guaraníes locales, Susana pareciera haber «perdido» su identidad indígena. Sin embargo, le salta la kuña cuando «cura el susto» ${ }^{12}$ o cuando baila el pim pim. Susana es hija de Eloísa, una anciana guaraní, y de Ricardo, un hombre de posible ascendencia alemana, a quien conoció cuando ya era adulta. Fue su hijo Damián quien se encargó de investigar la genealogía materna y, sin el consentimiento de Susana, llevarla al encuentro de su padre en San Salvador de Jujuy (capital provincial). En ese momento, Susana completó la otra parte de su historia y atribuyó su color de piel «mate» al entrevero de «sangre»: «¿No ves mi color? Yo no soy ni negra ni blanca, tengo un color mate. Y parece que allí fue el entrevero de sangre. Porque yo lo miro a mi papá, es rubio, parece que ha sido un hombre polaco, alemán». En ese momento, Susana no pudo disimular el asombro que le generaba la incompatibilidad de «razas» de sus padres: «No sé cómo se han juntado, porque si la ves a mi mamá, es una brasilera».

Al igual que Miriam, Susana no utiliza el término «guaraní» para describir su ascendencia. Incluso, utiliza el calificativo «brasilera» (asociado a lo «afro») para remarcar el color de piel oscuro de su madre. En otra dirección, el tío de Susana sostiene que su hermana Eloísa es de otra rama indígena, pero no guaraní. Más allá de las conjeturas familiares, la misma Eloísa se reconoce como guaraní, que solía comer wïtïmïmö (tipo de torta típica guaraní, hecha con harina de maíz), que entiende el idioma y reconoce variedades lingüísticas entre distintos pueblos: «El guaraní del paraguayo es igual que el guaraní de nosotros. El paraguayo es igual idioma, sino que el paraguayo dice palabras cantando y el chaguanco no. Dicen 'eyukuaepe' ['vení acá'], cortante, y los paraguayos dicen 'eyúkuaepé'». Eloísa también diferencia subgrupos y dialectos: «Tembeta ${ }^{13}$ es el que tiene una cosita acá metida [en la pera]. Guaraní todos. Ellos entienden. Tembeta, el chaguanco... Mataco no, indio tampoco. Pero el tembeta, el simba, chaguanco son todos, hablan igual. Son de distintos pueblos, pero hablan el mismo lenguaje».

12 El «susto» es considerada una enfermedad nativa que debe ser tratada por curanderos.

13 Tembeta significa «pasador labial»y, asimismo, es otra forma de denominar al subgrupo simba. 
Lo que me interesa subrayar es que, mientras Eloísa diferencia a los matacos de los guaraníes, Susana se identifica, alternada y simultáneamente, con distintos grupos indígenas o subgrupos: chaguanca, tembeta, mataca, chorote y aborigen. En su discurso, pareciera que todas estas categorías funcionan como sinónimos para referir a una identidad indígena genérica («aborigen») que, por momentos, y principalmente durante el pim pim, sale a la luz. Sin ser constante ni enteramente chaguanca, Susana lo es cuando le tira la sangre o cuando le salta la kuña.

La mayoría de las biografías de Calilegua entreveran sangre guaraní y sangre de otras «razas» (karai y colla, y en menor medida, indígena chaqueña, entre otras). Mientras que algunos eligen resaltar y visibilizar el componente guaraní, otros valoran todos los componentes de la mezcla — sin priorizar el guaraní- y la mezcla en sí misma. La exaltación guaraní adquiere relevancia en el proceso de reemergencia étnica que se fue gestando a partir de la conformación de las comunidades guaraníes en la década del 90 y del accionar de mburuvicha-reta como Gloria Pérez. En este sentido, la guaranización (que también podríamos denominar chaguanquización) podría entenderse como un proceso que opera en distintos niveles, desde lo personal hasta lo político, a través de mecanismos tanto reivindicativos como imperceptibles e inclasificables. Cabe aclarar que no se trata de un proceso unidireccional hacia la guaraneidad, sino que una misma persona puede, alternadamente, guaranizarse y desguaranizarse según la ocasión. Desde acciones individuales, como protegerse del sol para «blanquearse» y desguaranizarse, hasta contextos colectivos, como visibilizarse con mandu en un acto político, lo guaraní se esconde y se muestra, lo cual permite pensar en gradientes (más o menos guaraníes) y no tanto en conjuntos estáticos que se definen por contraste (guaraníes y no guaraníes).

Como muchos recuerdan, Rubén, primo de Susana y conocido artesano, escultor y artista plástico guaraní de Calilegua, era «bien chaguanco», es decir, «chaguanco puro». La dicotomía entre «chaguancos puros» y «chaguancos blancos» permite pensar en la existencia de gradientes de los guaraneidad mencionados. Como veremos, la «pureza racial» no está signada de modo determinante por la herencia biológica, sino que se encuentra influenciada por cuestiones del orden de la práctica (alimentación, alianzas matrimoniales, participación en el arete guasu, modos de ser y actuar), que se transmiten a través del compartir en contextos comunitarios. Una vez, Yanina comparó a su hija Lucrecia (de seis años de edad) con su sobrina Sofía (de cinco años de edad). Mientras que la primera fue definida como "chaguanquita pura» por su gusto por la chicha, la segunda fue descripta como «chaguanquita blanca». Ambas son primas entre sí, 
nietas de una curandera guaraní (Marta) y bisnietas de una curandera de Bananal (Elvira), pero la madre de Sofía no es de «raza guaraní». Con casi el mismo componente sanguíneo, las prácticas de cada niña varían: mientras que Lucrecia está permanentemente en el centro comunitario de la Kuape Yayemboati, Sofía solo tiene contacto con el mundo guaraní a través de su familia paterna. Lucrecia, en cambio, está presente cuando sus tías preparan chicha, sale bailando de tipoi en el arete guasu, y deambula siempre que hay asamblea comunitaria. Así, dentro de la Kuape Yayemboati, la oposición entre puros y blancos/blanqueados permite reflexionar en torno a la exaltación/ocultamiento guaraní, al peso de la «sangre» y a la importancia de la praxis.

Otra dicotomía que adquiere relevancia en los debates internos gira en torno a la participación comunitaria. Más que requisito excluyente para definir quién es y quién no es guaraní, dicha participación propicia la reflexión acerca de las nomenclaturas aparentemente impuestas (como chiriguano o chaguanco) y los modos relativos de ser guaraní, lo cual genera redescubrimientos de lo guaraní dentro de las propias biografías. De esta manera, Yanina supo que su abuela materna no solo era guaraní, sino que era una poderosa ipaye de la localidad de Bananal (departamento de Ledesma). De ningún modo se quita la guaraneidad a quienes no frecuentan las comunidades. De hecho, reconocidas curanderas guaraníes casi no salen de sus casas y se involucran poco en las actividades comunitarias por temor a exponerse y quedar implicadas en lazos brujeriles ${ }^{14}$. Sin embargo, para los jóvenes, el ámbito comunitario se constituye como un buen espacio de aprendizaje, transmisión de conocimientos, recuperación lingüístico-cultural y, por lo tanto, de guaranización (o, podríamos decir, en este caso, de reguaranización). En general, «los que van a las comunidades» se renuevan año tras año, lo cual da por resultado configuraciones comunitarias sumamente variables. Con esto quiero enfatizar que ser miembro activo (y participativo) de las comunidades es solo una forma de ser guaraní. En tanto fenómeno reciente, la organización en comunidades después de la década de 1990 no siempre se corresponde con el modo de ser guaraní de los más ancianos, quienes suelen recordar que «antes no había comunidades».

En suma, el «nosotros» que conforma la comunidad implica devenires, inconstancias, fluideces y heterogeneidades. Ciertos dualismos (como guaraní/

14 Jürgen Riester (1986) ha registrado, entre los izoseño-guaraní de Bolivia, que los ipayes no participaban en las asambleas ni en las faenas comunitarias y que raras veces se mezclaban entre la gente. 
karai, puro/blanqueado, miembros activos de las comunidades/miembros que no participan en ellas) son puestos en acción para conformar un nosotros en movimiento y reflexionar en torno al otro (que no es tan otro). Tales dualismos incluso operan dentro de una misma persona que, según la circunstancia, deviene guaraní (se guaraniza) o deviene otro (se desguaraniza), pero solo parcialmente: lo guaraní se mantiene en latencia.

\section{RAZAS GUARANIZADAS Y PUREZA ÉTNICA: USOS LOCALES DE LA CATEGORÍA «RAZA»}

La discusión acerca de las «razas» excede a los guaraníes y se constituye como una temática de reflexión local. Para Victoria (mujer de ascendencia colla), collas, chiriguanos y matacos (wichi) pueden ser todos englobados bajo una misma «raza» genérica, aborigen o indígena. No obstante, entre mis interlocutores guaraníes, los collas y los guaraníes jamás podrían ser incluidos en una misma «raza aborigen» (Sarra, 2019). Aborigen se utiliza como sinónimo de «guaraní» o de «chaguanco», y se opone tanto a la «raza» karai como a la colla.

Aunque el fenotipo y la herencia biológica sean factores importantes, para mis interlocutores, a la hora de definir las «razas», tales criterios no son, en lo absoluto, determinantes. El concepto de «raza», como categoría nativa, supone tanto características físicas y morfológicas, como cuestiones étnicas y culturales asociadas a distintos modos de ser y de actuar. La superposición semántica entre términos como «cultura», «tradición» $\mathrm{y}$ «raza» da cuenta de ello. En este sentido, la identificación racial de una persona no está dada de nacimiento, sino que es relativa a sus prácticas, elecciones y a la autoadscripción.

Durante muchos años, José, un guaraní adulto, ocultó su identidad por temor a la discriminación, es decir, se desguaranizó (o deschaguanquizó). «Yo no soy chaguanco», exclamaba. Si bien actualmente rechaza el etnónimo «chaguanco» por su carga peyorativa, en ese entonces, al afirmar «yo no soy chaguanco», buscaba negar su ascendencia indígena guaraní. Años más tarde, no solo se reconoció como guaraní sino que comenzó a hablar en la lengua materna (y paterna) y devino en un importante mburuvicha. El carácter racial heredado puede resultar, sin embargo, un dato menor en la autoadscripción de una persona a la «raza» guaraní. Así, nadie duda de la guaraneidad de Lucía, una mujer que, si bien desconoce sus raíces raciales, aprendió a «ser guaraní» de adulta, al estar presente en el cotidiano de su comunidad; es decir, se guaranizó. 
Aunque el matrimonio interracial no sea, según las enseñanzas de los abuelos ${ }^{15}$ guaraníes, recomendable, tales uniones suceden con frecuencia y se constituyen como modo recurrente de guaranización. Si bien los abuelos José Ramón y Lorenza Pascuala (ambos guaraníes) proscribían estrictamente los matrimonios mixtos, muchas de sus hijas y nietas desobedecieron el mandato. Como recuerda su nieta Marcela, algunas de sus tías tuvieron que sufrir por amor y decepción cuando querían formar familia con alguien que no fuese de la «raza» guaraní. «Mis abuelos siempre estuvieron ahí [diciendo] que ellos no son nuestra «raza» para que ellos formen familia», afirma. Tal fue el caso de su madre, quien tuvo que dejar, por mandato familiar, a su novio que era «un ingeniero rubio y de ojos celestes» que trabajaba en la empresa Ledesma. También fue el caso de Asunta, que tuvo una hija con un hombre de «otra raza». Ello le implicó conflictos familiares con sus padres, quienes nunca aceptaron tal unión. Cuando el hombre terminó abandonando a Asunta con su hija, sus padres encontraron más argumentos para su proscripción matrimonial. Sin embargo, el rechazo al matrimonio con otras «razas» no es generalizado y, en efecto, ocurre con frecuencia. Asunta es solo un ejemplo de las desobediencias recurrentes a dicho mandato guaraní, y no todos sufrieron el mismo castigo. Un tío de Marcela contrajo matrimonio con una mujer que era monja y dejó los hábitos por él. «Muy rubia, muy linda y muy guapa ['hacendosa'] la monja», la definió su sobrina. «A esa unión mi abuela no se interpuso», me contó asombrada Marcela, y concluyó risueña: «iquién entendía lo que querían los abuelos!».

Combès y Villar (2007) refirieron a tres tipos de uniones matrimoniales entre «razas» dentro de los guaraníes del piedemonte andino: entre personas de distintos subgrupos guaraníes (ava, isoseños y simbas), entre guaraníes e indígenas chaqueños, y entre guaraníes y karai. En Calilegua, la pertenencia a los subgrupos ava, simba e isoseño es mayormente desconocida, razón por la cual este tipo de unión no es considerada «entre razas». Entre mis interlocutores, son pocos los que recuerdan a qué subgrupo pertenecían sus padres. Uno de ellos es Renato, un hombre de la localidad de Fraile Pintado, quien sabe que él tiene las «variedades isoseña y ava mezcladas en su sangre». Respecto del segundo tipo de uniones, no he registrado ningún casamiento entre un guaraní y una persona de algún grupo indígena chaqueño, lo cual no quiere decir que no ocurran. Además

15 Los «abuelos» no son tan solo quienes tienen hijos que a su vez tienen hijos: los hijos de los hijos no crean la condición de abuelo. La edad es el factor determinante en la adquisición del estatus de abuelo o abuela. 
del matrimonio sumamente frecuente entre una mujer guaraní y un hombre karai, otro tipo de uniones merecen particular atención en Jujuy: es la que se da entre guaraníes y personas de ascendencia colla. De ambas posibilidades (casamiento con colla o con karai), el casamiento con karai es preferencial. Corina, nieta de José y Lorenza, se juntó («unió en matrimonio») y tuvo dos hijos con un hombre de Libertador General San Martín, quien sospecha tener ascendencia colla. Su prima Yolanda se juntó con Jorge, un hombre karai de Formosa. Si bien Jorge es karai, algunos insinúan que, dado su origen formoseño, podría tener algún componente indígena en su sangre. Así, Yanina opina que él es guaraní pero que, como no investigó sus raíces, no lo sabe. De cualquier modo, Yolanda afirma que su marido «tuvo que hacerse aborigen a la fuerza». Bajo esta lógica de conversión por matrimonio, sucesivas veces sugirieron que yo misma debía juntarme con un hombre guaraní si quería completar mi proceso de guaranización. Según Yolanda, los karai «no tenemos cultura» y somos más fáciles de convertir que, por ejemplo, los collas.

La preservación de la «raza» fue una preocupación de los antiguos guaraníes que prescribían los matrimonios entre guaraníes y, así, evitaban el entrevero. Marcela me relató que cuando sus abuelos llegaron desde Bolivia, se instalaron todos juntos en un mismo barrio de Calilegua, el barrio Estrella: «Nos quedamos a vivir ahí todos parientes, primos, hermanos, primos con otros primos, hermanos con otros hermanos, formaron pareja, pero siempre somos familia del otro». El entrevero periurbano, la disolución de barrios y los casamientos entre «razas» ocurrieron en simultáneo, estableciendo un quiebre entre «el tiempo de los abuelos» y las generaciones actuales. Tal como recuerda la anciana ipaye Romelia, «los jefes de Ledesma se hacían los pícaros y tenían hijos con mujeres indígenas», lo cual dio por resultado «el entrevero de sangre».

La cuestión del mestizaje entre indígenas y blancos, y la consecuente pérdida cultural, ha consternado no solo a los abuelos guaraníes sino también a varios investigadores, como Erland Nordenskiöld, Thierry Saignes y Hernando Sanabria (Villar y Combès, 2007). Sin embargo, el mestizaje es prexistente al contacto con el blanco, tal como sugiere el paradigmático caso del origen mestizo de los chiriguano-chané (Villar y Combès, 2007). Isabelle Combès y Villar (2007) sostuvieron que la ideología de la estirpe y la pureza es un rasgo propiamente arawak. La «ideología de la estratificación social» asociada a la «sangre», la «pureza» y la «raza», que se encuentra extendida entre guaraníes de Argentina y Bolivia, corresponde en realidad a una institución de origen arawak (chané e isoseña) (2007, p. 47). Entre los chané, tienen importancia las jerarquías y linajes 
cacicales (castas de guerreros, la pertenencia se hereda por línea paterna) (Villar, 2013). La afiliación a familias cacicales es cuestión de sangre, herencia e incluso «raza», y asociarse con la élite es ser «más chané» que los demás (Villar, 2013). En la actualidad, el aumento contemporáneo de matrimonios interétnicos, llamados «cruzados» o «entreverados», es percibido como consecuencia directa de la declinación del poder cacical (Villar, 2013). El origen mestizo chiriguano-chané contrastaría, paradójicamente, con la búsqueda de la pureza racial que este grupo pretende alcanzar. La aparente paradoja que encierran estos grupos, calificados como los «mestizos más puros» se resuelve cuando los autores afirman que «no existe ni jamás existió una disolución absoluta de la identidad colectiva en el magma del mestizaje» (Combès y Villar, 2007, p. 53).

Según Combès y Villar (2007), no se trata, tan solo, de una constatación etnohistórica, sino que tiene implicancias en la reivindicación étnica, la memoria oral, el reciclaje onomástico y el reconocimiento genealógico. Esto puede dar una clave para entender lo que muchos de mis interlocutores pretenden expresar cuando afirman «sin nombre, sin identidad». Con esa frase, hacen referencia al arbitraje con el cual les fueron impuestos nombres en los documentos de identidad, sin respetar lazos de parentesco. Es por ello que los hermanos José Ramón, Eusebio Segundo, Juan Marcelino, Juan Ireyo y Julio Romero tienen apellidos distintos. Así como hermanos de sangre tienen apellidos diferentes, es frecuente que dos personas con el mismo apellido — «Segundo» es un apellido muy común en Calilegua - no sean parientes. Victoria me explica que se ponían apellidos arbitrariamente, no por parentesco, sino por filas: Primero, Segundo, Tercero, Cuarto, Quinto. «En Calilegua está lleno de Segundos y Terceros. Primeros hay muchos en Embarcación [Salta]», me dice. El interés por la preservación de la «raza» y los nombres - o, dicho en otras palabras, la pureza de sangre expresada en el nombre-, pareciera resultar inviable en el contexto del Ramal, que entrevera, constantemente, apellidos y razas.

¿Es posible pensar que el escenario tan multiétnico del Ramal, y del piedemonte andino en general, propició, paradójicamente, el rechazo - al menos discursivo- a la mezcla, o es que dicho debate ya existía entre los guaraníes del piedemonte incluso antes del contexto del ingenio? Tanto en Argentina como en Bolivia — recuerdan Villar y Combès (2007) — los indígenas considerados «mestizos» no son bien vistos por los demás. Si bien la exigencia de pureza podría derivar de un requisito de autenticidad indígena ante los Estados, creo que es necesario repensar la categoría nativa de pureza racial a la luz de la praxis. El análisis de Federico Bossert (2007) sobre las categorías de «raza» y «pureza», 
utilizadas por los chané de Tuyunti (Salta), resulta esclarecedor. La coexistencia de un alto grado de mestizaje con una fuerte ideología de pureza fue interpretada por el autor no como una homogeneidad ficticia y estratégica hacia el exterior (es decir, hacia el Estado, las instituciones, ONG, la Iglesia, etcétera), sino como resultado de mecanismos de asimilación. Entre dichos mecanismos, enumera: la localidad, la adopción de hábitos corporales y de comportamiento y, fundamentalmente, la adopción de las variaciones idiomáticas locales. Los hijos de matrimonios entreverados (chané con individuos ava o isoseños) serán asimilados dentro de la «raza» «chané» en la siguiente generación (Bossert, 2007, p. 332). En Calilegua la asimilación opera de manera más abierta, incorporando la otredad de los karai, collas y otras personas que, en principio, no se reconocen como guaraníes. De los mecanismos mencionados por Bossert (2007), la adopción de hábitos corporales y de comportamiento parecieran ser las principales formas de incorporación de otras «razas» en Calilegua.

Antes que circunscribir una élite cerrada y dada por nacimiento, la «raza» guaraní, como conjunto abierto, y sujeto a criterios múltiples y transformables, permite la permanente inclusión de otras «razas». En su análisis de la onomástica aweti, Marina Vanzolini (2019) indagó en la noción amerindia de descendencia asociada menos a una condición dada de nacimiento que a una situación construida: los jefes aweti son construidos e individualizados a través del acto de otorgarles un nombre que posee cualidades específicas que le son transferidas a la persona nombrada. Lo que la autora enfatizó es la necesidad de amerindianización de la categoría antropológica clásica de descendencia (y, vinculada a ella, la noción de linajes): en el mundo amerindio, esta está más asociada a la producción de diferencia que a la semejanza y continuidad.

Del mismo modo, se podría postular la pertinencia de una amerindianización de las categorías étnicas, menos ligadas a la identidad y a lo dado que a la alteridad y a lo construido. Más que esencia dada de antemano, lo guaraní se construye, se modela y se transforma. Mediante uniones matrimoniales mixtas, participación comunitaria y otras prácticas, los de afuera pueden pasar a formar parte de los de adentro sin mucho protocolo ni testimonio de identidad. Si los otros pueden devenir nosotros, la alteridad puede devenir identidad.

En suma, la pretendida pureza racial podría ser entendida como una «eliminación» de la diferencia que se produce tras haber previamente incorporado al otro y a su alteridad. Más que una forma de repliegue hacia el interior, los discursos y prácticas sobre la pureza podrían ser leídos como un mecanismo de relación con la alteridad. La búsqueda de pureza racial, entonces, puede coexistir con una 
transformación permanente ${ }^{16}$. En el contexto actual, «guaraní» tal vez no deba ser entendido como algo del orden de la identidad sino del devenir, de lo que se vuelve y transforma, permanentemente, en algo distinto de «sí mismo».

\section{COMUNIDADES NO SOLO HUMANAS. DEVENIR-DUEÑO}

Tras el cambio de estado que actualiza la muerte, uno de los posibles destinos de los humanos es devenir dueños protectores de aquello hacia lo que, en vida terrenal, como humanos, sintieron atracción. El mburuvicha Marcelo, en reiteradas ocasiones, me describió el lugar adonde se dirigen los arete iya («dueños del ritual del arete guasu»): el pueblo no-humano Mati Moröcho, situado en un lugar cosmológico en medio del monte y en el centro del continente sudamericano, donde moran algunos antepasados guaraníes, aquellos a quienes les gustaba mucho el arete guasu. Allí, los ex humanos, devenidos dueños, viven en casas de barro y techo de paja («como las de antes», aclara Marcelo), disfrutan de un arete guasu interminable, bailan, tocan música y toman chicha. Mati Moröcho es una hipérbole del ritual terrenal. Mati Moröcho es un pueblo no-humano, entre otros.

En los guaraníes del piedemonte andino, todas las cosas son poseídas, administradas y reguladas por múltiples entidades denominadas iya reta («dueños»): emociones, objetos, seres y elementos de la naturaleza (como el agua, los ríos, peces, el jaguareté, los pájaros), fiestas, instrumentos musicales, grupos étnicos, entre tantas cosas, tienen sus respectivos dueños (ver también Villar, 2005). Cada uno de los iya reta pertenece a un mundo social no-humano. Así, existe el mundo de los jaguares, el mundo acuático de la dueña de los peces, el mundo regido por el dueño del palo borracho, entre otros. Estos mundos son conocidos a través de la experiencia subjetiva (sueños, visiones durante paseos por el monte y en el

16 Estas ideas dialogan con el análisis que José Kelly (2016) realiza a partir de su etnografía sobre los yanomami de Venezuela. Entre los yanomami, el mestizaje no postula una «fusión consuntiva de la diferencia, sino la adición de una socialidad diferente» (p. 52). Si con un imperativo expansivo los criollos buscaron incorporar o asimilar la diferencia indígena con la expectativa de transformar al otro en un «yo», la relación de la cultura yanomami con la cultura criolla es inversa: incorpora la diferencia mediante una transformación del «yo» en un otro. Sobre esta base, el autor propone llamar «antimestizaje» a esta segunda teoría de la hibridación a la cual subyace una idea de transformación permanente por contraposición al ideal de pureza que implicaría el mestizaje. Kelly sostiene que asumir una posición de alteridad es, entre los yanomami, una cuestión performativa para afectar a otra persona. Entre los guaraníes se observa una doble dinámica: se transforman a sí mismos en otros (provisoriamente) y, al mismo tiempo, en una dinámica expansiva, transforman a los otros en guaraníes. Lo interesante es que la praxis, en ambos casos, es la que permite las transformaciones. 
ámbito ritual) de, principalmente, guaraníes especialistas (ipaye-reta, cazadorespescadores, «mascaritas»). Como dichas experiencias no siempre coindicen, la organización sociocosmológica de estos mundos es terreno de discusión al interior de los guaraníes. Mientras que algunos sostienen que existen distintos dueños del monte, hay quienes afirman que existe un máximo dueño o dueña de él.

Ignacia, anciana guaraní de Calilegua, que en su juventud fue una gran cazadora-recolectora, afirma que existe una dueña del monte que es llamada (podríamos suponer que por influencia andina) «Pachamama». Esta mujer rubia y blanca adopta, cría y alimenta a los animales cuyas madres son heridas por los cazadores inescrupulosos. Aquí, la relación entre la dueña del monte y sus posesiones-animales es de una «filiación adoptiva» (Fausto, 2008). En una misma sintonía, Isidro, cazador-pescador adulto de Calilegua, me explicó que la relación entre el dueño o dueña del monte y sus animales es la misma que aquella que un humano entabla con sus mascotas. En sus términos, existe un dueño máximo (o dueña, ya que, en sus reflexiones, el género es indefinido), denominado Ari o Pachamama, indistintamente. Por debajo de su posición, hay un sinnúmero de entidades protectoras que, según Isidro, se acostumbra a designar «dueños» pero pueden ser mejor definidas como "subdueños» que tienen a su cargo un terreno particular. La relación entre el dueño máximo y las demás entidades es, ya no de parentesco, sino de carácter sociopolítico: existen jerarquías entre el dueño y el resto de los no-humanos que habitan el monte.

La asimetría no solo se refleja en la mayor jerarquía de los dueños respecto de sus posesiones (y de los dueños respecto de subdueños), sino también en las relaciones que los dueños entablan con los humanos ${ }^{17}$. Como describía al comienzo de este apartado, los dueños son ex-humanos y, por ende, parientes lejanos de los humanos terrenales. La categoría «dueños» supone relaciones asimétricas en múltiples niveles: entre dueños y posesiones (animales, por ejemplo), entre dueños y otras entidades de menor categoría, y entre dueños y humanos. Los dueños, en tanto antepasados, denominan «hijos» a sus parientes terrenales, y los humanos, por su parte, llaman «abuelos» a los dueños. La continuidad antepasados-dueños parecería acercar el dominio de los dueños al ámbito de los

17 En la última década, la discusión en torno a los «dueños» no-humanos en sociedades indígenas de tierras bajas sudamericanas ha reverberado en la etnografía americanista (Bonilla, 2005; Cesarino, 2010; Daillant, 2003; Fausto, 2008; Kohn, 2007; Santos Granero, 2009; Tola, 2012). Las etnografías han desarrollado distintos aspectos de los dueños, así como las relaciones que los humanos mantienen con ellos. Algunas temáticas abordadas son las relaciones de poder, la sumisión, el control, la asimetría, el cuidado y la agencia. 
humanos y diferir, en cierto modo, del carácter prototípico que habitualmente se atribuye a los dueños en los mundos amerindios. Entre alteridad radical, parentesco lejano y familiaridad, los dueños-antepasados entablan distintas relaciones con sus parientes terrenales que, según el contexto, oscilan entre la distancia y la cercanía, y entre la explicitación de la asimetría y la difuminación de ella en pos de una consubstancialización entre vivos y muertos.

Si bien las comunidades del Ramal no disponen de territorios autónomos para su subsistencia, los pobladores locales ingresan esporádicamente a los fragmentos irregulares de monte - que aún resisten entre hectáreas de cañaverales de la empresa Ledesma - para pescar, cazar, recolectar frutos, juntar leña o simplemente pasear. Los modos de ingresar al monte siguen ciertos protocolos de respeto que implican, en líneas generales, instancias de pedido de permiso denominadas yerure y entrega de ofrendas (hojas de coca, tabaco y vino) al dueño del monte (la dueña o los dueños). Si bien yerure significa en sentido estricto «pedir, rogar por algo», varios de mis interlocutores denominan yerure tanto al pedido de permiso como a la entrega de ofrendas. Dichos modos presentan variaciones individuales e Isidro enfatiza que lo importante es entrar con respeto, escuchar a los dueños no-humanos y estar atento a sus señales y pedidos. Él, por ejemplo, no entrega ofrendas al dueño antes de entrar al monte, pero está en un estado permanente de atención: si está tomando vino y el vaso empieza a temblar, él ya sabe que el dueño le está pidiendo que le convide. «Ya te doy, pedime vino y no me andes asustando», le responde mientras convida vino al dueño. Al cabo de un tiempo, el vino pierde el sabor y se transforma en agua coloreada, porque el dueño consumió el alcohol. En otras oportunidades, Isidro se cruza con el dueño bajo la forma canónica de tres hombres a la vera del río. Ellos le piden cigarrillos y él siempre les da. «Por allá vas a encontrar mucho pescado», le informó una vez uno de los hombres en recompensa por su generosidad. Por el contrario, la arrogancia de quienes se adentran en el monte es castigada. En una ocasión, José fue a pescar con un compañero que se negó a convidarle vino al dueño. En castigo, el dueño lo desorientó y lo hizo perder en su camino de regreso. En un sentido similar, Ignacia me explicó que un hombre llegó una vez a la casa del monte de la Pachamama y fue raptado por ella en castigo por su comportamiento irresponsable.

En el ritual del arete guasu, los antepasados no son temidos, sino que se acercan a sus parientes terrenales y comparten jocosamente con ellos. Bajo la apariencia unificada de enmascarados, parientes ultraterrenales y parientes terrenales conforman un «nosotros» indiferenciado. Dentro de los cuerpos de los vivos, o como enmascarados anónimos, los muertos participan de la fiesta terrenal, 
danzan, toman chicha y tocan música en el ritual terrenal. En sintonía con los registros etnográficos de Villar y Bossert (2014), los guaraníes hacen chistes, se ríen a carcajadas y se emborrachan durante el arete guasu. Incluso bromean con las máscaras puestas; máscaras rituales que permiten la incorporación parcial de los antepasados en el cuerpo de los vivos ${ }^{18}$. Después de todo, están compartiendo y festejando con sus parientes («muertos», pero parientes al fin), a quienes sin duda se les debe un trato respetuoso, pero con quienes también es posible bromear, reírse, bailar y tomar alcohol. «Son ellos que nos buscan para compartir y joder [bromear] con nosotros», me explicó un «mascarita».

Bajo la forma de dueños, personajes enmascarados o «espíritus», los antepasados continúan formando parte de la comunidad de los vivos. Si bien para cualquier guaraní los vínculos con distintos seres no-humanos son algo del orden de lo natural, esto no excluye que tales encuentros generen desasosiego. Muchos guaraníes, habituados a la vida periurbana, prefieren no adentrarse en el monte debido a la abundancia de entidades no-humanas que acechan allí. No obstante, las experiencias de encuentros con ellas son cotidianas en Calilegua, sobre todo en la época del arete guasu. Al fin del arete de 2019, Noelia, una joven de veinte años, «vio» (en sueños) a sus abuelos que se despedían antes de volver a su morada no-humana. «Los soñó bien clarito como ellos eran, pese a que cuando ellos murieron, ella era muy chiquita y casi ni los vio», me explicó su suegra. El sueño, para los guaraníes, guarda cierto parentesco con la observación y experiencia directa ${ }^{19}$. Es por ello que, cuando mis interlocutores dicen que vieron o hablaron con sus abuelos, muchas veces están aludiendo a una experiencia onírica (y no por ello, menos concreta). Esto no excluye que las relaciones de intercambio y comunicación entre humanos y no-humanos sean frecuentes también en plena vigilia, cuando los cazadores pasean por el monte o cuando los enmascarados bailan con los muertos en el ritual. En los meses previos al ritual del arete, algún antepasado suele presentarse ante Isidro para indicarle con qué máscara quiere que su contraparte humana (Isidro) salga bailando (Sarra, 2020). Una vez, él me dijo: «La verdad no sé si lo vi o lo soñé, pero [el antepasado] me pidió que lo recuerden». Si bien el sueño es ámbito privilegiado de comunicación humana-no-

18 Si bien el proceso de enmascaramiento no produce una alteración de la identidad del humano que porta una máscara de un antepasado, el enmascarado es transformado parcialmente por la presencia de un antepasado en su propio cuerpo (Sarra, 2020).

19 Entre los mbyá-guaraní, Pierri (2013) hace referencia al conocimiento que es adquirido a través de sueños. Cadogan (1992) traduce el verbo exara'u — que se compone de exa, que quiere decir «observar»y de ra'u, que refiere al estado onírico. Como «ver en sueños». 
humana, los guaraníes dialogan e intercambian (presas, ofrendas, imágenes) con los ex humanos tanto en el mundo onírico como en la vigilia, lo cual evidencia la materialidad tangible de los no-humanos, en relación de continuidad con los humanos y la centralidad que poseen en la socialidad guaraní.

\section{PALABRAS FINALES}

Los procesos de guaranización y desguaranización, la incorporación de la alteridad a través de la práctica y la potencial transformación final en «dueños» concuerdan con las observaciones de Viveiros de Castro (1992) acerca de los grupos tupí-guaraní como polo arquetípico de los sistemas amerindios abiertos. La transformación tupinambá de los cautivos en cuñados expresaba la paradójica «interna exterioridad» de los enemigos, que, a nivel escatológico, el antropólogo brasileño observó entre los araweté (Viveiros de Castro, 1992). Aunque necesariamente egocentrada en el nivel local, la estructura social tupinambá no tenía sujeto ni centro y estaba constituida en su relación-con-el-enemigo: la venganza era su fundamento (Viveiros de Castro, 1992). En síntesis, el centro está afuera, la identidad está en otro lado y el otro no es un espejo en el que me miro, sino que es mi destino (Viveiros de Castro, 1992).

En términos del antropólogo, la transformación está en el corazón de la sociedad tupinambá (Viveiros de Castro, 1992). En un sentido similar, la persona araweté está inherentemente en transformación y el destino humano es un proceso de devenir otro (Viveiros de Castro, 1992). Salvando las distancias, la concepción fluida y transformacional de la persona y de los grupos entre los guaraníes del Ramal, podría ser comprendida bajo este modelo tupí-guaraní.

En un artículo sobre onomástica chané, Villar y Bossert (2004) realizaron una crítica a la postulación de los tupí-guaraníes como polo arquetípico de dichos sistemas abiertos, predatorios o exonímicos, que toman sus nombres del ámbito extrasocial (categoría que engloba a dioses, enemigos, animales y muertos). Dichos autores remarcaron que los enemigos no pueden ser conceptualizados como «exteriores» a la sociedad humana de igual modo que las divinidades y los muertos. En sus términos, el problema surgiría en relación con la delimitación de fronteras entre afueras y adentros en cada grupo. ¿Qué sucede, por ejemplo, con el caso de plantas y animales? ¿Son estos «extrasociales»o «intrasociales»? (Villar y Bossert, 2004, p. 66). En otras palabras, ¿cómo definir si «algo» es exterior o forma parte de la interioridad del grupo? 
Una posible respuesta sería que la misma imposibilidad de delimitar afueras y adentros separados entre sí sea lo que define al dinamismo amerindio, por el cual una entidad definida como ajena es, en otra circunstancia, pensada como propia. En este sentido, sería inútil establecer de antemano conjuntos extrasociales o intrasociales, pues todo depende de la provisoria posición perspectiva que se adopte. Las entidades protectoras del entorno son consideradas parientes por los guaraníes, son denominados «abuelos», y junto con ellos, los humanos conforman un «nosotros» que habita en comunidades humanas y más-que-humanas, en una geografía sociocosmológica. Asimismo, antepasados-dueños representan la diferencia radical respecto de los humanos. La diferencia, sin embargo, no es tipo sino de grado: los mundos no-humanos, como el Mati Moröcho, son una hipérbole de los mundos terrenales. Además, los antepasados-dueños se relacionan de distintos modos con sus parientes terrenales y pueden, incluso, penetrar en sus cuerpos, fusionándose con ellos. Esta consubstacialización humano-no-humano nos remite al plano socioétnico, a identidades entreveradas que coexisten en una misma persona y a la guaranización. Así como los no-humanos pueden ingresar en cuerpos humanos, lo «guaraní» puede entreverarse con la alteridad, guaranizar a quienes no lo son y crear consanguinidad a través de la práctica. Al igual que la relación de continuidad entre humanos y no-humanos, la diferencia entre lo guaraní y lo no-guaraní no es tajante sino que admite gradientes, procesos de guaranización, desguaranización y reguaranización, y, al mismo tiempo, la latencia de una pureza en el entrevero.

\section{REFERENCIAS}

Bonilla, Oiara (2005). O bom patrão e o inimigo voraz: predação e comércio na cosmologia paumari. Mana: Estudos de Antropologia Social, (2), 41-66. https://doi. org/10.1590/S0104-93132005000100002

Bossert, Federico (2007). Los chané del río Itiyuro; continuidades y transformaciones en la organización social, Tesis de Doctorado. Facultad de Filosofía y Letras, Universidad de Buenos Aires.

Bossert, Federico (2013). Ingenios azucareros y relaciones interétnicas. En P. Sendón y D. Villar, Al pie de los Andes. Estudios de etnología, arqueología e historia (pp.163-185). Bolivia: Itinerarios.

Braunstein, José y Miller, Elmer (1999). Ethno-historical introduction. En E. Miller, Peoples of the Gran Chaco (pp. 1-22). Wesport: Bergin \& Garvey. 
Cadogan, León (1992). Diccionário Mbya-Guarani - Castellano. Asunción: Fundación León Cadogan/CEADUC/CEPAG.

Cesarino, Pedro de Niemeyer (2010). Donos e duplos: propriedade e replicação entre os Marubo. Revista de Antropologia da USP, 53 (1), 147-197.

Combès, Isabelle y Villar, Diego (2007). Os mestiços mais puros: Representações chiriguano e chané da mestiçagem. Mana, 13(1), 41-62. https://doi.org/10.1590/ S0104-93132007000100002

Descola, Philippe (2016). La composición de los mundos. Conversaciones con Pierre Charbonnier. Buenos Aires: Capital Intelectual.

Daillant, Isabelle (2003). Sens dessus dessous: Organisation sociale et spaciale des chimane d'Amazonie bolivienne. Nanterre: Société d'Ethnologie.

Fausto, Carlos (2008). Donos demais: maestria e propriedade na Amazônia. Mana: Estudos de Antropologia Social, 14, 329-366. https://doi.org/10.1590/S010493132008000200003

García Moritán, Matilde y Cruz, María Beatriz (2012). Comunidades originarias y grupos étnicos de la Provincia de Jujuy. Población y Sociedad, 19(2), 155-173.

Goldman, Marcio (2017). Contradiscursos Afroindígenas sobre Mistura, Sincretismo e Mestiçagem. Estudos Etnográficos, Revista de Antropologia da UFSCAR, 9(2), 11-28.

Gordillo, Gastón (2010a). Deseando otro lugar: reterritorializaciones guaraníes. En G. Gordillo y S. Hirsch (comps.), Movilizaciones indígenas e identidades en disputa en la Argentina (pp. 207-236). Buenos Aires: La Crujía.

Gordillo, Gastón (2010b). Lugares de Diablos. Tensiones del espacio y la memoria. Buenos Aires: Prometeo Libros.

Gow, Peter (1991). Of mixed blood. Kinship and history in Peruvian Amazonia. Oxford: Clarendon Press.

Hirsch, Silvia (2000). Tirando el mal del otro lado de la frontera: brujería e identidad cultural entre los guaraníes de Bolivia y Argentina. Revista de Investigaciones Folclóricas, 15, 35-41.

Hirsch, Silvia (2004a). Ser guaraní en el noroeste argentino: variaciones de la construcción identitaria. Revista de Indias, 14(230), 67-80.

Hirsch, Silvia (2004b). Mbaporenda: el lugar donde hay trabajo. Etnohistoria. Recuperado el 28/04/18 de http://etnohistoria.equiponaya.com.ar/htm/04_abstract.htm

Hirsch, Silvia (2014). Mujeres guaraníes, vínculos transnacionales e identidades en la frontera argentino-boliviana. En J. M. Valenzuela Arce (coord.), Transfronteras: 
las fronteras del mundo y procesos culturales (pp. 237-254). México: Colegio de la Frontera Norte.

Jerez, Omar (2011). Los guaraníes y los procesos de vinculación: trabajo y educación. Una mirada sobre los guaraníes en San Pedro de Jujuy. En E. Cruz, Historia y etnicidad en las Yungas de Argentina (pp. 31-44). Salta: Purmamarka Ediciones.

Kelly, José (2016). Sobre a antimestiçagem. Florianópolis: Cultura e Barbárie.

Kohn, Eduardo (2007). Animal masters and the ecological embedding of history among the Avila Runa of Ecuador. En C. Fausto y M. Heckenberg (eds.), Time and Memory in Indigenous Amazonia. Anthropological Perspectives. Florida: University Press of Florida, 106-131.

Langer, Erick (2009). Expecting Pears from and Elm tree: Franciscan Missions on the Chiriguano Frontier in the Heart of South America, 1930-1949. Durham-Londres: Duke University Press. https://doi.org/10.1215/9780822390916

Pierri, Daniel (2013). Como acabará essa terra? Reflexões sobre a cataclismologia Guarani-Mbya, à luz da obra de Nimuendajú. Tellus, 24, 159-188.

Riester, Jürgen (1986). Aspectos del chamanismo de los Izoceño-Guaraní. Suplemento Antropológico, 21(13), 263-283.

Rivera Cusicanqui, Silvia (2010). Ch'ixinakax utxiwa: uma reflexión sobre prácticas y discursos desconolizadores. Buenos Aires: Tinta Limón.

Saignes, Thierry (1990). Ava y Karai. Ensayos sobre la frontero chiriguano (siglos XVI$X I X)$. La Paz: Hisbol.

Saignes, Thierry e Isabelle Combès (1991). Alter Ego. Naissance de l'identité chiriguano. París: EHESS/Cahiers de l'Homme.

Santamaría, Daniel (2010). Cambio e identidad entre los guaraníes del Ramal Jujeño. Jujuy: PurmamarkaEdiciones.

Santos Granero, Fernando (2009). Vital enemies: slavery, predation, and the Amerindian political economy of life. Austin: University of Texas Press.

Sarra, Sonia (2019). La catástrofe de Volcán desde la perspectiva de los guaraníes de Jujuy: topologías, grupos étnicos y no-humanos desde los guaraníes del piedemonte andino (Jujuy, Argentina). Revista Chilena de Antropología, 39, 77-103.

Sarra, Sonia (2020). El pasado está en el futuro. Historicidad y espacio-tiempo verdadero entre los guaranies de Jujuy [tesis de doctorado]. Facultad de Filosofía y Letras, Universidad de Buenos Aires.

Stengers, Isabelle (2005). The Cosmopolitical Proposal. En B. Latour y P. Weibel (eds.), Making Things Public (pp. 994-1003). Cambridge: MIT Press. 
Susnik, Branislava (1968). Chiriguanos 1. Dimensiones etnosociales. Asunción: Museo Etnográfico «Andrés Barbero».

Tola, Florencia (2012). Yo no estoy solo en mi cuerpo. Cuerpos-Personas múltiples entre los tobas del Chaco Argentino. Buenos Aires: Editorial Biblos/Culturalia.

Vanzolini, Marina (2019). The Name of the Relation. Making a Difference in Aweti Onomastics. Social Analysis, 63(2), 102-121. https://doi.org/10.3167/ sa.2019.630206

Villar, Diego (2005). La religión Chané [tesis de doctorado]. Buenos Aires: Facultad de Filosofía y Letras (UBA).

Villar, Diego (2013). Modelos de liderazgo amerindio: una crítica etnológica. En P. Sendón y D. Villar (eds.), Al pie de los Andes. Estudios de etnología, arqueología e historia (pp. 11-31). Cochabamba: Itinerarios.

Villar, Diego y Federico Bossert (2004). La onomástica chané en clave etnográfica y comparativa. Acta Americana, 12(1), 49-78.

Villar, Diego y Federico Bossert (2014). Máscaras y muertos entre los chané. Separata (19), 12-33.

Viveiros de Castro, Eduardo (1992). From the enemy's point of view. Humanity and Divinity in an Amazonian Society. Londres: The University of Chicago Press.

Viveiros de Castro, Eduardo (1996). Os pronomes cosmológicos e o perspectivismo ameríndio. Mana, 2(2), 115-144. https://doi.org/10.1590/ S0104-93131996000200005 